\title{
Understanding Consumer Pork Attribute Preferences
}

\author{
Ann M. Cummins ${ }^{1}$, Nicole J. Olynk Widmar ${ }^{1 *}$, Candace C. Croney ${ }^{2}$, Joan R. Fulton ${ }^{1}$ \\ ${ }^{1}$ Department of Agricultural Economics, Purdue University, West Lafayette, USA \\ ${ }^{2}$ College of Veterinary Medicine, Purdue University, West Lafayette, USA \\ Email:amcummins@msn.com, “nwidmar@purdue.edu,ccroney@purdue.edu,fultonj@purdue.edu
}

Received 25 February 2016; accepted 3 April 2016; published 6 April 2016

Copyright (C) 2016 by authors and Scientific Research Publishing Inc.

This work is licensed under the Creative Commons Attribution International License (CC BY).

http://creativecommons.org/licenses/by/4.0/

cc) (i)

Open Access

\begin{abstract}
The best-worst scaling method was used to investigate consumers' perceptions of the relative importance of seven different pork production and product attributes. Demographic information was then analyzed to determine which consumer characteristics were statistically significant determinants of these preferences. Of the attributes studied, animal welfare was ranked third most important following pork/food safety and taste. Consumer characteristics including gender, having a source for animal welfare information, and having purchased pork in the last year were found to be determinants of the size of the share of preference for many of the pork attributes studied.
\end{abstract}

\section{Keywords}

Consumer Preferences, Consumer Demand, Best-Worst Scaling, Market Analysis

\section{Introduction}

Consumers' levels of concern for the welfare and treatment of livestock animals continue to be a topic of conversation in the media, academic research, and throughout the agricultural industries and food marketplace. A key focus for livestock producers, marketers, and retailers alike is understanding consumer preferences for meat product attributes. Today consumers have an increased ability to make consumption choices based on information about the livestock product itself, as well as the quality of life of the animal from which the product was derived. Given the increased access to and speed of obtaining information, it is important to better understand how consumers make tradeoffs in attributes (consciously or subconsciously) when making purchasing decisions so

*Corresponding author. 
that producers and retailers can better meet their demands.

Consumers consider a wide variety of attributes when making purchasing and consumption decisions for food products. Lusk and Briggeman [1] studied eleven different food values, namely, naturalness, taste, price, safety, convenience, nutrition, tradition, origin, fairness, appearance, and environmental impact. The top three food values identified as most important to consumers were safety, price, and taste. There is evidence in recent literature that production and product attributes are also important in consumption decisions associated with meat and milk products. Both production and product attributes of livestock products have been studied using a variety of methods. Recent literature aimed at understanding consumer's preferences for meat and milk products, has investigated the study of a wide variety of attributes. Consumers are increasingly concerned with production processes including animal welfare, food safety, environmental impact, and other social implications, and they take these into consideration in their purchasing decisions [2]. Sackett, Shupp and Tonsor [3] studied consumers' preferences for beef production attributes within the context of sustainability and specifically looked at attributes including antibiotic use, animal health and safety, farm size, geographic level of production, and consumer food price. Vanhonacker et al. [4] examined consumer's prioritization of farm animal welfare relative to other food product attributes of safety, quality, reliability, taste, origin, health, price, appearance, freshness, environmental friendliness, availability, and production method.

Commonly used methods to better understand consumers and their perspectives and demand for livestock products include using choice experiments (to analyze consumers' willingness to pay for different product attributes) or best-worst scaling (to determine underlying values of consumers' preferences). In recent literature, the use of correlations or regression analysis to examine different types of relationships between these preferences and demographic or socio-economic factors is also common. Examples of such studies include Kendall, Lobao, and Sharp [5] who studied determinants of consumers' attitudes toward farm animal welfare and determined that factors of importance included gender, age, income, education, experience with animals and a multitude of other factors.

Pork has been a livestock product which has received much attention in recent academic literature and popular press. Much of the conversation specific to pork production has been about production practices related to pig welfare. In the past decade there have been several studies on consumers' willingness to pay for verified pork production attributes. Tonsor, Olynk and Wolf [6] examined the use of gestation crates and discussed increasing interest in production practices in the meat industry, including antibiotic or growth hormone use, local production, and animal friendly handling practices. Olynk, Tonsor and Wolf [2] studied pasture access, individual crates/stalls, antibiotic use, trucking/transportation, and certification entities for pork chops. Similarly, McKendree et al. [7] studied pasture access, individual crates/stalls, antibiotic use, and verification entities for smoked ham and ham lunchmeat. While there are many attributes of pig production that consumers may consider when purchasing and consuming pork, McKendree, Croney, and Widmar [8] found that $14 \%$ of U.S. consumers had reduced their consumption of pork products (in the 3 years prior to the study) due to animal welfare concerns. Recent studies of consumers' preferences for pork attributes commonly involve consumers' willingness to pay for verified credence attributes. One question of interest then becomes understanding how production and product attributes compare within a continuum of importance for consumers.

To address this question seven pork attributes were investigated. Animal welfare, environmental impacts, locally raised/farmed pigs, and locally processed pork were analyzed in order to incorporate some of the commonly discussed production attributes. These four attributes were studied in combination with the three product attributes identified by Lusk and Briggeman [1] as important food values, namely price, food safety, and taste.

The objective of this analysis was to examine the tradeoffs amongst pork attributes when making purchasing decisions by utilizing a best-worst scaling estimating consumer preference for pork attributes. Additionally, this analysis investigated the relative importance of these attributes and the relationship between preference and consumer demographics, pet ownership, and sources used for animal welfare information. Our goal was to gain insight on consumers' preferences for each pork attribute. We specifically wanted to determine the key pieces of demographic information that are statistically significant determinants of the size of the share of preference for each of the pork attributes studied. Given that when analyzing the determinants of the shares of preference for each attribute, the standard errors could be correlated between the models we use seemingly unrelated regression analysis. Seemingly unrelated regressions allow for simultaneous estimation of the set of models while at the same time accounting for correlated errors [17]. 


\section{Materials and Methods}

\subsection{Survey Instrument and Data}

The dataset used for this analysis was from a nationally representative U.S. consumer survey. The dataset was collected utilizing an online questionnaire, which was developed and hosted in Qualtrics at Purdue University. The survey (questionnaire) was designed to elicit consumers' preferences for various aspects of pork production, including attributes of the production system as well as attributes of meat (pork). Survey participants were contacted by Light speed GMI, the manager of a large opt-in panel. The sample was targeted to be representative of age, gender, pre-tax income and region of residency. Respondents were required to be at least 18 years of age to participate. The survey data was collected using the online survey mechanism from July 23 through August 6, 2014. Information collected in this survey included respondent demographic information, the response to a validation question, as well as responses to a best worst scaling problem set.

A total of 1004 completed responses were collected. In total 1924 individuals clicked on the survey link (entered the survey) at some point during the data collection process, although 1004 completed the survey in its entirety during the data collection time period. Thus, $52 \%$ of those respondents who clicked on the survey link to enter the survey completed it during the data collection time period. Table 1 contains the basic demographics of the survey respondents compared with the census statistics for age [9], gender [9], and income [10] and geographic location of residence [11].

\subsection{Maximum Difference Scaling}

Maximum difference scaling, commonly referred to as best-worst scaling, was originally used by Finn and Louviere [12]. The best-worst scaling analysis was explained more thoroughly by Marley and Louviere [13] who clarified the underlying method. The method used by Lusk and Briggeman [1], which utilized recent advances in this type of modeling, was adapted for this analysis to ultimately determine consumers' shares of preference for each of the studied pork attributes. This method forces survey participants to make tradeoffs between attributes of a particular subject. In this analysis, participants were forced to make tradeoffs between seven pork attributes. The specific attributes involved in this study were: animal welfare, price, pork/food safety, taste, environmental impacts, locally raised/farmed pigs, and locally processed pork.

The best-worst scaling methodology has advantages over the commonly used Likert-scale-type questions or ranking-type questions which seek the same general insight. When participants are asked to rank attributes in relative importance the result is only the rank (also referred to as order). Ranking-type questions do not provide a way for understanding the magnitude of importance of the individual attributes relative to one another. It is easy for participants responding to Likert-scale types of questioning to classify all attributes as important or equally on the scale, both of which are pitfalls to the rating question type according to Lusk and Briggeman [1]. Also, the rating method scale can be interpreted differently by different individuals making the results unclear. According to Wolf and Tonsor ([14], pg. 231) "unlike, for example, the Likert-scale-type questions, best-worst scaling is cardinal;" thus it allows the analyst to determine the ordering (or rank) of attributes in addition to establishing how important attributes are to consumers.

To determine both ordering and relative importance of the seven pork attributes for consumers, best-worst scaling was utilized. A balanced incomplete block design that optimized positional frequencies and allowed for question sets of equal size was used. Respondents were asked to indicate from a set of four pork attributes which attribute in the question (choice set) shown was the most important (best) and the attribute that was the least important (worst) to them when they purchased pork. Every respondent saw the same seven choice sets, where each choice set showed four attributes. Each attribute was shown four times within the best-worst design and all possible best-worst pairs had the potential to be made two times throughout the seven choice sets. Within each choice set respondents were unable to select the same attribute in a choice set as both the most and least important.

\subsection{Best-Worst Analysis}

The best-worst question presented 7 pork attributes $(K)$ to consumers, thus $K=7$ for this analysis. There was a total of $K(K-1)=42$ best-worst combination possibilities any individual consumer could make. Given that consumers were shown seven choice sets with four attributes each, consumers had the opportunity to make 
Table 1. Demographics of survey respondents.

\begin{tabular}{|c|c|c|c|}
\hline \multirow{2}{*}{ Variable description } & $\begin{array}{l}\text { Survey } \\
(\mathrm{n}=1004)\end{array}$ & $\begin{array}{l}\text { Passed validation test } \\
\qquad(\mathrm{n}=857)\end{array}$ & Census \\
\hline & Frequency (\%) & Frequency (\%) & Frequency (\%) \\
\hline Female & 50 & 50 & 51 \\
\hline \multicolumn{4}{|l|}{ Age } \\
\hline 18 to 24 years & 8 & 7 & 13 \\
\hline 25 to 44 years & 39 & 37 & 35 \\
\hline 45 to 64 years & 36 & 37 & 35 \\
\hline 65 years and over & 17 & 19 & 17 \\
\hline \multicolumn{4}{|l|}{ Household income } \\
\hline Less than $\$ 25,000$ & 22 & 20 & 23 \\
\hline$\$ 25,000$ - \$34,999 & 11 & 12 & 11 \\
\hline$\$ 35,000$ - \$49,999 & 15 & 16 & 14 \\
\hline$\$ 50,000-\$ 74,999$ & 20 & 20 & 18 \\
\hline$\$ 75,000$ - \$99,999 & 13 & 13 & 12 \\
\hline$\$ 100,000$ - \$149,999 & 13 & 14 & 13 \\
\hline$\$ 150,000$ or more & 6 & 5 & 9 \\
\hline \multicolumn{4}{|l|}{ Education } \\
\hline Did not graduate from high school & 2 & 1 & \\
\hline Graduated from high school & 18 & 17 & \\
\hline $\begin{array}{l}\text { Attended college, } \\
\text { No degree earned }\end{array}$ & 22 & 22 & \\
\hline $\begin{array}{l}\text { Attended college, associate or } \\
\text { trade degree earned }\end{array}$ & 14 & 15 & \\
\hline $\begin{array}{l}\text { Attended college, bachelor's } \\
\text { (B.S. or B.A.) degree earned }\end{array}$ & 29 & 28 & \\
\hline $\begin{array}{l}\text { Graduate or advanced degree } \\
\text { (M.S., Ph.D., law school) }\end{array}$ & 15 & 17 & \\
\hline Other & 0 & 0 & \\
\hline \multicolumn{4}{|l|}{ Region of residence } \\
\hline Northeast & 19 & 18 & 18 \\
\hline South & 37 & 37 & 38 \\
\hline Midwest & 24 & 25 & 22 \\
\hline West & 20 & 20 & 22 \\
\hline
\end{tabular}

twelve combinations per question leading to a total of 84 combination possibilities (12 combinations per question $\times 7$ questions $=84$ combinations). Participants' $i$ 's latent, unobservable, level of importance of the attribute $k$ was $I_{i k}=\lambda_{k}+\varepsilon_{i k}$ where $\lambda_{k}$ was the location of $k$ on the underlying scale of importance of pork attributes, and $\varepsilon_{i k}$ was the random error term. If $\varepsilon_{i k}$ are i.i.d. type 1 extreme value, then the probability of any specific one attribute chosen as most important and any other chosen specific attribute as least important was of the multinomial logit (MNL) form following Lusk and Briggeman [1], shown in equation (1).

$$
\operatorname{Prob}(k \text { is chosen "best" and } w \text { chosen "worst" })=\frac{\mathrm{e}^{\lambda_{k}+\lambda_{w}}}{\sum_{l=1}^{K} \sum_{m=1}^{K} \mathrm{e}^{\lambda_{l}+\lambda_{m}}-K}
$$


Then, $\lambda_{k}$ was estimated with the maximum of the log-likelihood function. The pair of attributes takes on the value 1 for the pair that the individual chose as most and least important, and 0 for the remaining pairs not chosen by the participant. The estimated $\lambda_{k}$ was thus the value of attribute $k$ relative to the attribute that was normalized to zero in the estimation of the model.

Current literature suggests there is evidence of heterogeneity of consumer preferences. Therefore consumer preference models that account for heterogeneity have been utilized in many recent studies [1] [2] [6] [15]. The random parameters logit model (RPL), also known as mixed logit, is commonly used to account for heterogeneity in preferences amongst individuals. Following Lusk and Briggeman [1] the RPL model was used in this analysis to account for consumer heterogeneity. The RPL model makes modifications from the MNL form such that $\lambda_{k}$ which was the location on the underlying scale of importance of the value $k$ in the MNL form is then specified to be different for each individual $i$ and takes the form $\tilde{\lambda}_{i k}=\bar{\lambda}_{k}+\sigma_{k} \mu_{i k}$, where the population mean and standard deviation of $\lambda_{k}$ is $\bar{\lambda}_{k}$ and $\sigma_{k}$ respectively, and $\mu_{i k}$ is the random term that is specified to be normally distributed with the mean equal to zero. Following Train [16] and Lusk and Briggman [1] $\tilde{\lambda}_{\mathrm{ik}}=\bar{\lambda}_{k}+\sigma_{k} \mu_{i k}$ is substituted into Equation (1) and then the RPL is estimated by simulation. This estimation was completed in NLOGIT 5.0 using Halton draws for $\mu_{i k}$ which seeks to maximize the simulated log-likelihood function.

The RPL model assumes that $\varepsilon_{i k}$ is equal to one. The random error term, however, can vary between persons and thus it is possible that the mean of the parameter estimates of $\lambda_{k}$ may be confounded with differences in scale. Thus the results from the parameter estimates in the RPL model are not easily interpretable. Following Lusk and Briggeman [1] to address the potential confound in scale the shares of preference, $S$, (the forecasted probability that the attribute $k$ is chosen as best) were calculated following Equation (2) for each pork attribute examined.

$$
S_{k}=\frac{\mathrm{e}^{\lambda k}}{\sum_{w=1}^{Z} \mathrm{e}^{\lambda w}}
$$

The shares of preference for each of the seven attributes sum to one by design. Individual consumer-specific shares of preference for each of the seven attributes as well as the mean preference share for the entire dataset are estimated ${ }^{1}$. Shares of preference "can be analyzed to reveal cardinal rankings and respondent characteristics associated with those rankings” ([14], pg. 222). Individual-specific shares of preference facilitate analysis of relationship between shares; relationships were evaluated utilizing correlations completed in SPSS.

\subsection{Seemingly Unrelated Regression Analysis}

To gain deeper insight into the potential relationships between the size of the share of preference for the pork attributes and consumer demographics, a seemingly unrelated regression was used. The intended goal was to determine which key pieces of demographic information were statistically significant determinants of the size of the share of preference for each of the pork attributes studied. When attempting to analyze determinants of the shares of preference for each attribute, it is possible that the standard errors could be correlated between the models. Seemingly unrelated regressions allow for simultaneous estimation of the set of models while at the same time accounting for correlated errors [17], thus the seemingly unrelated regression was used.

The specific models used in this analysis were specified such that the dependent variables were the size of the share of preference for each attribute and the set of independent variables in each regression were the same set of key demographics along with the result of a simple validation test result (pass vs. fail) ${ }^{2}$. The set of specific demographic factors studied included gender, age (using 65 and older as the base category), income (with a base category of greater than $\$ 150,000$ ), college education, pet ownership, having a source for animal welfare, diet type and pork purchasing behavior. Following the seemingly unrelated regression, Wald tests were employed such that the null hypothesis was that the coefficient estimate for an independent variable across the set of equations was concurrently equal to zero. The seemingly unrelated regression analysis and related testing was com-

\footnotetext{
${ }^{1}$ There are two ways to calculate the mean share of preference for each attribute. One way is to calculate the mean of the individual calculated preference shares for each attribute (using individual-specific coefficient estimates obtained in NLOGIT 5.0). The second option is to use the mean parameter estimates from the RPL model. In this work the latter is used to calculate mean shares of preference for each sample as utilizing the individual-specific preference shares facilitates calculation of correlations between preference shares and demographics for individual respondents.

${ }^{2}$ Survey respondents were asked to select the number six from the options one through seven. Those who correctly select the number six are considered to have "passed" and all others were considered to have "failed" the validation question.
} 
pleted in Stata 12.

\section{Results and Discussions}

The importance of each pork attribute was relative to the attribute locally processed pork (the least important attribute according to the estimated RPL model); results are shown in Table 2. Since individual coefficients are not meaningful on their own, the calculation of the shares of preferences (using the mean parameter estimates) for each attribute are also presented in Table 2. These shares of preference values were interpreted as the probability that a consumer would select the attribute as most important. For example, the size of the share of preference for Pork/Food Safety was 0.406, meaning that the probability that a consumer would select pork/food safety as most important (out of the list of attributes) was $40.6 \%$, approximately. The relative ranking of the pork attributes from most important to least important was as follows: pork/food safety, taste, animal welfare, price, environmental impact, locally raised pigs and locally processed pork. The mean preference share for animal welfare was ranked third largest following pork/food safety and taste, and immediately preceding the attribute price. It is not surprising that pork/food safety was most important to consumers; this remains consistent with many previous studies including Lusk and Briggeman [1] who found that food safety was approximately twice as important as the next two most important attributes of price and taste. In our analysis, the attribute, animal welfare, was ranked in the midst of the top three food values found by Lusk and Briggeman [1] which implies that animal welfare in livestock-derived food products, particularly pork, is important to consumers.

To gain deeper insight into potential relationships among shares of preference for the seven attributes studied, correlations amongst individual-specific preference shares were analyzed. The correlations (and their significance) between shares of preference are shown in Table 3 . The size of the share of preference for animal welfare was statistically significant and negatively correlated with the size of the share of preference for the attributes, price, safety, and taste; meanwhile, it was statistically significant and positively correlated with the size of the share of preference for environmental impact, locally raised/farmed pigs and locally processed pork. The size of the share of preference for price was statistically significant and negatively correlated with the size of the share for all other attributes, excluding taste; this is reassuring in that participants that had larger preference shares for price tended to trade it off with the other attributes, as would be expected.

\section{Exploring Determinants of Relative Preferences for Pork Attributes}

To gain deeper insight into the potential relationships between the size of the shares of preference for the pork attributes and consumer demographics, the seemingly unrelated regression was completed. Coefficient estimates,

Table 2. RPL results and shares of preference for pork attributes.

\begin{tabular}{|c|c|c|c|}
\hline & \multicolumn{2}{|c|}{ Econometric estimates } & \multirow{2}{*}{ Shares of preference } \\
\hline & Coefficient & Standard deviation & \\
\hline Animal welfare & $\begin{array}{l}1.4711^{* * *} \\
(0.0570)\end{array}$ & $\begin{array}{l}1.4555^{* * *} \\
(0.0557)\end{array}$ & 0.156 \\
\hline Price & $\begin{array}{l}0.9971^{* * *} \\
(0.0727)\end{array}$ & $\begin{array}{c}2.4569^{* * *} \\
(0.0783)\end{array}$ & 0.097 \\
\hline Pork/food safety & $\begin{array}{l}2.4303^{* * *} \\
(0.0598)\end{array}$ & $\begin{array}{l}1.4013^{* * *} \\
(0.0609)\end{array}$ & 0.406 \\
\hline Taste & $\begin{array}{l}1.7969^{* * *} \\
(0.0534)\end{array}$ & $\begin{array}{l}1.1923^{* * *} \\
(0.0555)\end{array}$ & 0.215 \\
\hline Environmental impact & $\begin{array}{l}0.3583^{* * *} \\
(0.4891)\end{array}$ & $\begin{array}{l}1.2010^{* * *} \\
(0.0608)\end{array}$ & 0.051 \\
\hline Locally raised/farmed pigs & $\begin{array}{l}0.0952^{* *} \\
(0.0442)\end{array}$ & $\begin{array}{l}0.9170^{* * *} \\
(0.0601)\end{array}$ & 0.039 \\
\hline Locally processed pork & 0 & & 0.036 \\
\hline
\end{tabular}

Note: Individuals made 7 choices and there were 1004 individuals, thus there were 7028 observations. ${ }^{* * *},{ }^{* *},{ }^{*}$ indicate statistical significance at $1 \%$, $5 \%, 10 \%$ level respectively. 
Table 3. Correlations of shares of preference between pork attributes $(n=1004)$.

\begin{tabular}{|c|c|c|c|c|c|c|c|}
\hline & $\begin{array}{l}\text { Animal } \\
\text { welfare }\end{array}$ & Price & $\begin{array}{l}\text { Pork/food } \\
\text { safety }\end{array}$ & Taste & $\begin{array}{l}\text { Environmental } \\
\text { impacts }\end{array}$ & $\begin{array}{l}\text { Locally } \\
\text { raised/ } \\
\text { farmed pigs }\end{array}$ & $\begin{array}{c}\text { Locally } \\
\text { processed } \\
\text { pork }\end{array}$ \\
\hline Animal welfare & 1 & & & & & & \\
\hline Price & $-0.490^{* *}$ & 1 & & & & & \\
\hline Pork/food safety & $-0.068^{*}$ & $-0.481^{* *}$ & 1 & & & & \\
\hline Taste & $-0.070^{*}$ & -0.059 & $-0.167^{* *}$ & 1 & & & \\
\hline Environmental impacts & $0.336^{* *}$ & $-0.279^{* *}$ & 0.033 & $0.108^{* *}$ & 1 & & \\
\hline $\begin{array}{l}\text { Locally raised/ } \\
\text { farmed pigs }\end{array}$ & $0.285^{* *}$ & $-0.278^{* *}$ & $-0.068^{*}$ & $0.280^{* *}$ & $0.361^{* *}$ & 1 & \\
\hline Locally processed pork & $0.379^{* *}$ & $-0.296^{* *}$ & -0.043 & $0.360^{* *}$ & $0.526^{* *}$ & $0.798^{* *}$ & 1 \\
\hline
\end{tabular}

Note: Statistical significance (2-tailed) at the $5 \%$ and $1 \%$ level is represented by ${ }^{*}$ and ${ }^{* *}$ respectively.

"R-squared”, and chi $^{2}$-statistic information for the seemingly unrelated regression are displayed in Table 4. Each model has a chi ${ }^{2}$ statistic which is statistically significant at the $0.1 \%$ statistical significance indicating that the set of independent variables in each model are statistically significant. Immediately following the regression analysis, the set of tests was completed to determine if each independent variable was statistically different from zero across all models. The null hypothesis was that the coefficient estimate for an independent variable across the set of equations is concurrently equal to zero. The resulting p-values from these tests are presented in Table 5. If the value is less than 0.05 then it can be interpreted as the coefficient estimates associated with the particular variable examined was statistically different from 0 across all of the seven models.

Results from the seemingly unrelated regression revealed that being male and having purchased pork in the previous year were statistically significant determinants of the size of the share of animal welfare and had negative coefficient estimates. This finding supports those by Vanhonacker et al. [4] who found that men attached less importance to animal welfare relative to other production characteristics of livestock products than did women. Vanhonacker et al. [4] also found evidence of differences between consumption of meat products and concern for animal welfare which indicated that heavy meat consumers cared less about animal welfare relative to other production characteristics when compared with individuals reporting moderate or low meat consumption. Statistically significant determinants of the size of the shares of animal welfare preference with positive coefficient estimates included individuals in the age category 25 - 44 years old, individuals selecting income $\$ 50,000$ to $\$ 74,000$, having a source for animal welfare information, owning a dog, and owning a cat.

It is expected in primary data collection that the researcher make efforts to obtain the best data quality possible. Both survey design and data collection techniques are important elements commonly discussed regarding obtaining quality data. Guidelines for survey development, design, and administration so as to improve data quality have been discussed by many, including Dillman [18]. Various validation methods have been investigated in order to help identify participants who are not responding sincerely. The use of different data improvement methods and enhancements to these methods continue to be analyzed for the impacts in data quality improvement. The recent focus on attribute non-attendance in choice experiments [19] [20] and the study of relatively simple validation questions [21] is evidence of interest in enhanced data quality controls. Validation questions are simple questions embedded within the survey or data collecting instrument to identify participants who are alert, reading, and understanding survey questions. These questions are simple to incorporate, do not take long for participants to answer, and the results (passing or failing the validation question test) can be applied to multiple questions or aspects of the survey. In their study of consumers' willingness to pay for different animal products, Gao, House, and $\mathrm{Bi}$ [21] found, when examining the impact of a validation test, that there were differences between those who passed and those who did not pass the validation test. Gao, House, and Bi [21] suggested that the inclusion of a validation question would be a way to "detect careless respondents in the survey and improve data quality". Thus, one question in the survey asked respondents to select the number six from the options one through seven. Those who correctly selected the number six were considered to have "passed" the validation test. Those who did not select six were considered to have "failed" the test. Eighty-five percent of 
Table 4. Seemingly unrelated regression results.

\begin{tabular}{|c|c|c|c|c|c|c|c|}
\hline & \multicolumn{7}{|c|}{ Models } \\
\hline & $\begin{array}{l}\text { Animal } \\
\text { welfare }\end{array}$ & Price & $\begin{array}{c}\text { Food/pork } \\
\text { safety }\end{array}$ & Taste & $\begin{array}{l}\text { Environmental } \\
\text { impacts }\end{array}$ & $\begin{array}{l}\text { Locally raised/ } \\
\text { farmed pigs }\end{array}$ & $\begin{array}{l}\text { Locally } \\
\text { processed } \\
\text { pork }\end{array}$ \\
\hline Passed validation test & $0.0389^{* *}$ & $-0.0422^{*}$ & $0.0839^{* * *}$ & $-0.0386^{* * *}$ & $-0.0167^{* * *}$ & $-0.0154^{* * *}$ & $-0.0097^{* * *}$ \\
\hline Male & $-0.0505^{* * *}$ & $0.0337^{* *}$ & $-0.0304^{* *}$ & $0.0419^{* * *}$ & 0.0038 & -0.0001 & $0.002^{*}$ \\
\hline 18 to 24 years & 0.0365 & -0.0019 & $-0.0667^{* *}$ & 0.0265 & 0.0045 & 0.0003 & 0.0004 \\
\hline 25 to 44 years & $0.0456^{* * *}$ & 0.0254 & $-0.0846^{* * *}$ & -0.0015 & 0.0040 & $0.0091^{*}$ & 0.0018 \\
\hline 45 to 64 years & 0.0020 & $0.0604^{* *}$ & $-0.0553^{* *}$ & -0.0058 & -0.0024 & 0.0019 & -0.0017 \\
\hline Income less than 25,000 & 0.0297 & $0.0907^{* *}$ & -0.0420 & $-0.0569^{* *}$ & -0.0119 & -0.0082 & -0.0028 \\
\hline Income 25,000 - 34,999 & 0.0313 & $0.1203^{* * *}$ & $-0.0771^{*}$ & $-0.0514^{* *}$ & -0.0107 & -0.0112 & -0.0034 \\
\hline Income 35,000 - 49,999 & 0.0214 & $0.1021^{* *}$ & $-0.0789^{* *}$ & -0.0284 & $-0.0158^{*}$ & 0.0001 & -0.0020 \\
\hline Income 50,000 - 74,999 & $0.0458^{*}$ & 0.0614 & -0.0412 & $-0.0493^{* *}$ & -0.0112 & -0.0034 & -0.0033 \\
\hline Income 75,000 - 99,999 & 0.0330 & 0.0548 & -0.0419 & $-0.0429^{*}$ & -0.0083 & 0.0026 & 0.0013 \\
\hline Income 100,000 - 149,999 & -0.0103 & 0.0469 & -0.0317 & -0.0078 & -0.0045 & 0.0074 & 0.0007 \\
\hline College educated & -0.0048 & 0.0189 & $-0.0282^{*}$ & 0.0074 & 0.0057 & 0.0007 & 0.0006 \\
\hline $\begin{array}{l}\text { Has a source for animal } \\
\text { welfare information }\end{array}$ & $0.0415^{* * *}$ & $-0.0452^{* * *}$ & -0.0094 & -0.0149 & $0.0165^{* * *}$ & $0.0074^{* *}$ & $0.004^{* * *}$ \\
\hline Owns a dog & $0.0228^{*}$ & -0.0215 & 0.0000 & -0.0093 & 0.0024 & 0.0031 & $0.0022^{*}$ \\
\hline Owns a cat & $0.026^{* *}$ & -0.0170 & -0.0153 & -0.0067 & 0.0049 & 0.0038 & $0.0029^{* *}$ \\
\hline Purchased pork in the last year & $-0.0425^{* * *}$ & -0.0107 & $0.0427^{* *}$ & $0.0389^{* * *}$ & $-0.0175^{* * *}$ & -0.0072 & $-0.0032^{* *}$ \\
\hline Vegetarian & 0.0210 & -0.0459 & 0.0026 & -0.0254 & $0.0365^{* * *}$ & 0.0102 & 0.0008 \\
\hline Vegan & 0.0066 & -0.0372 & -0.0418 & -0.0121 & $0.0247^{*}$ & $0.0472^{* * *}$ & $0.0128^{* * *}$ \\
\hline _cons & $0.107^{* * *}$ & $0.1602^{* * *}$ & $0.371^{* * *}$ & $0.2101^{* * *}$ & $0.0722^{* * *}$ & $0.0484^{* * *}$ & $0.0322^{* * *}$ \\
\hline R-sq & 0.0840 & 0.0441 & 0.0566 & 0.0566 & 0.1074 & 0.0877 & 0.1230 \\
\hline chi $^{2}$ & 92.11 & 46.28 & 60.24 & 60.2 & 120.81 & 96.57 & 140.78 \\
\hline $\mathrm{p}$ & 0.0000 & 0.0003 & 0.0000 & 0.0000 & 0.0000 & 0.0000 & 0.0000 \\
\hline
\end{tabular}

Note: ${ }^{* * *},{ }^{* *},{ }^{*}$ indicate statistical significance at $1 \%, 5 \%, 10 \%$ level respectively.

respondents passed the validation test question.

In addition to demographics for the entire sample, Table 1 displays the summary of those who passed the validation question. Statistically significant correlations existed between passing the validation test and income (positive correlation relationship), age (18 - 44 was negatively correlated with passing, age 65 years and older was positively correlated with passing the validation test), as was higher education at the $5 \%$ significance level. This finding is similar to Gao, House, and $\mathrm{Bi}$ [21] who found that respondents who failed the validation test tended to be younger, less educated, and had lower incomes.

Overall, passing the validation test question was a statistically significant determinant in each of the models evaluated. Thus this implies that passing the validation test is a statistically significant determinant when predicting the shares of preference for each of these seven pork attributes and implies that making use of a simple validation question within a best-worst analysis has the possibility of impacting the results.

While some people choose not to eat livestock-derived products, or meat products, there are many different reasons why individuals may choose to not purchase pork specifically. For example, religious beliefs may prohibit the consumption of pork products, individuals may not like or enjoy pork (relative to other meats), or consumers may be opposed to eating pigs (but find eating other species acceptable). Thus, pork consumption and purchasing was studied specifically by asking respondents to indicate if they had purchased pork in the past year. 
Table 5. Test of the hypothesis that the coefficient for each independent variable is zero for all 7 outcome variables.

\begin{tabular}{cl}
\hline Variable & p-value \\
\hline Passed validation test & 0.0000 \\
Male & 0.0000 \\
18 to 24 years & 0.4219 \\
25 to 44 years & 0.0039 \\
45 to 64 years & 0.1154 \\
Income less than 25,000 & 0.0763 \\
Income 25,000 - 34,999 & 0.0211 \\
Income 35,000 - 49,999 & 0.0787 \\
Income 50,000 - 74,999 & 0.1219 \\
Income 75,000 - 99,999 & 0.2183 \\
Income 100,000 - 149,999 & 0.8572 \\
College educated & 0.6033 \\
Has a source for animal welfare information & 0.0000 \\
Owns a dog & 0.3190 \\
Owns a cat & 0.0075 \\
Vegetarian & 0.0001 \\
Purchased pork in the last year & 0.0520 \\
\hline
\end{tabular}

Eighty-three percent of respondents indicated they had purchased pork within the last year. Results indicate that having purchased pork in the last year was a statistically significant determinant of the size of the share of preference for the attribute animal welfare and had a negative coefficient estimate.

Kendall, Lobao, and Sharp [5] found that a key determinant of attitude about animal welfare was people's animal related experiences, including pet ownership. Rothgerber and Mican [22] examined the relationship between pet ownership (primarily focusing on childhood pet ownership) and its relationship to empathy towards animals and meat avoidance in adulthood. They concluded that connections to living animals and empathy for animals were related to pet ownership, but that "these affections for living animals did not transfer to decisions about whether to eat them" [22]. Given the implied linkage between pet ownership and stronger preferences for animal welfare, the current analysis included pet ownership (dog ownership, and cat ownership) as predictors of the size of the share of each attribute. McKendree, Croney and Widmar [8] found that $48 \%$ of households owned a dog and $41 \%$ of households owned a cat in the United States. Similarly, in this sample, $40 \%$ of participants owned cats and $46 \%$ of participants owned dogs. The results of the multivariate multiple regression revealed that owning a dog or cat were both statistically significant determinants of the size of the share of preference for animal welfare and both had positive coefficient estimates. Therefore, these results support the notion of a linkage between pet ownership and concern for animal welfare.

In McKendree, Croney and Widmar [8] pet owners (owners of dogs and/or cats) were found to be statistically more concerned for livestock animal welfare than non-dog and/or cat owners. They hypothesized that owning a pet may then also be related to seeking out animal welfare information given that pet owners more frequently reported having a source for animal welfare information. In addition, they examined relationships between reported concern for animal welfare and primary sources of animal welfare information. Their study found that an individual's level of concern for animal welfare was related to whether or not they had a source for animal welfare information, but no statistical differences were found between which sources was used [8]. In our analysis, $46 \%$ of the participants indicated that they had a primary source for animal welfare information. Given the potential impact of having a source for animal welfare information and the importance of the different attributes, the multivariate multiple regression included a predictor variable which was called "Has a source for animal 
welfare information” and was given a 1 if the individual indicated they had a source for animal welfare information, and 0 otherwise. The variable of having a source for animal welfare information was a statistically significant determinant of the size of the share of preference for the attribute animal welfare and had a positive coefficient estimate, which supports the previous findings. In addition, having a source for animal welfare information was also a statistically significant determinant in models predicting the size of the share of preference for the attributes environmental impacts, locally raised/farmed pigs, and locally processed pork. In each case the variable had a positive coefficient estimate. Having a source for animal welfare information was a statistically significant predictor of the size of the share of price, but had a negative coefficient estimate.

The size of the share of preference for locally processed pork had the most similar set of statistically significant determinants to the share of animal welfare. In addition to having a source for animal welfare, owning a dog or cat, was also statistically significant with positive coefficient estimates determinants of the size of the share of locally processed pork. Similar to determinants of the size of the share for animal welfare, having purchased pork in the last year was also a determinant of the size of the share for locally processed pork (and the size of the share of environmental impacts) with a negative coefficient estimate. Being vegan was a statistically significant predictor of the size of the share of environmental impacts, locally raised/farmed pigs and locally processed pork and in each of these three models had a positive coefficient estimate. Indicating that one was vegetarian was also a statistically significant determinant of the size of the share of environmental impacts and had a positive coefficient estimate.

The attribute of price ranked fourth most important following pork/food safety, taste, and animal welfare, but preceding environmental impacts, locally raised/farmed pigs and locally processed pork. The statistically significant determinants with positive coefficients for the size of the share of preference for price were male, 45 - 64 years old compared to 65 years or older, and lower pre-tax income (compared with income of $\$ 150,000$ or more). Determinants of the size of the share of preference for price with negative coefficient estimates were having a source for animal welfare information and passing the validation test. The coefficient estimate sign was generally opposite of the sign for each attribute when predicting shares of preference for the other attributes, which makes sense given that the size of the share of preference for price was found to be negatively correlated with the majority of the other shares of preference for the different attributes.

Pork/food safety was found to be the most important attribute, in keeping with other studies of consumers' preferences or concerns for animal products. Of the independent variables examined, being male, being in any of the age categories (other than 65 years and older), being college educated, and indicating household pretax income of $\$ 25,000$ to $\$ 34,999$ or $\$ 35,000$ - $\$ 49,999$ (compared to pretax income of $\$ 150,000$ or more) were all statistically significant determinants of the size of the share for pork/food safety with negative coefficient estimates. Having purchased pork in the last year and having passed the validation test were the only statistically significant determinants with positive coefficient estimates.

Taste was also ranked as one of the most important attributes. Seemingly unrelated regression results revealed that being male and having purchased pork in the previous year were statistically significant determinants of the size of the share of taste and had negative coefficient estimates. Independent variables associated with four income categories (less than $\$ 25,000$, $\$ 25,000$ to $\$ 34,999$, $\$ 50,000$ to $\$ 74,999$, and $\$ 75,000$ to $\$ 99,999$ ) (compared to the income category $\$ 150,000$ or more) as well as having passed the validation test were found to be statistically significant determinants of the size of the share of preference for taste.

\section{Conclusions}

Given consumers' increased interest in and abilities to make purchase decisions based on information about how food producing animal are reared, this study attempted to expand current understanding about what factors might be related to consumers' preferences, and the relative importance to consumers of different production and product attributes of pork when making consumption choices. Furthermore, these findings support the notion that making use of a simple validation test can provide different results, ultimately assumed to be more accurate.

The best-worst scaling method was used to determine the cardinal order and share of preference for the seven pork attributes studied: pork/food safety (40.6\%), taste (21.522\%), animal welfare (15.6\%), price (9.7\%), environmental impact (5.1\%), locally raised/farmed pigs (3.9\%) and locally processed pork (3.6\%). It is imperative to understand the level of importance placed on animal welfare, in particular, to further understand consumer's 
preferences when purchasing livestock products and specifically pork products, given the media coverage and attention to pork production practices in the recent past. The mean parameter estimate for animal welfare was ranked third in importance following pork/food safety and taste and prior to price, implying that when consuming livestock products, animal welfare is an important attribute to some consumers.

This examination of the shares of preference for pork attributes in the U.S. found that determinants in explaining the size of the share of preference for these different attributes included different consumer's demographics, pet ownership and sources of animal welfare information. These findings support previous studies which found a relationship between pet ownership and concern for livestock animal welfare. The majority of U.S. consumers did not have a primary source for animal welfare information, but having a source for animal welfare information was found to be a determinant with a positive coefficient estimate for each of the following attributes: animal welfare, environmental impacts, locally raised/farmed pigs and locally processed pork. Overall, consumers' relative level of importance placed on animal welfare was predicted by gender, age, having a source for animal welfare information and having purchased pork in the past year.

\section{Acknowledgements}

Researchers at Purdue University developed the concept for this study in collaboration with Fair Oaks Farms, Belstra Milling Co., Indiana Pork and Indiana Soybean Alliance. Indiana Pork and Indiana Soybean Alliance provided the funding for the study. Researchers at Purdue University conducted the study and analysis without input, collaboration, sharing of survey design or participation in data collection by the funders, Fair Oaks Farms or Belstra Milling Co. in order to avoid biases or the perception of biases arising from working with industry groups.

\section{References}

[1] Lusk, J. and Briggeman, B. (2009) Food Values. American Journal of Agricultural Economics, 91, 184-196. http://dx.doi.org/10.1111/j.1467-8276.2008.01175.x

[2] Olynk, N.J., Tonsor, G.T. and Wolf, C.A. (2010) Consumer Willingness to Pay for Livestock Credence Attribute Claim Verification. Western Agricultural Economics Association, 35, 264-280.

[3] Sacket, H.M., Shupp, R. and Tonsor, G. (2013) Consumer Perceptions of Sustainable Farming Practices: A Best-Worst Scenario. Agricultural and Resource Economics Review, 42, 275-290.

[4] Vanhonacker, F., Verbeke, W., Van Poucke, E. and Tuyttens, F.A.M. (2007) Segmentation Based on Consumers’ Perceived Importance and Attitude toward Farm Animal Welfare. International Journal of Sociology of Food and Agriculture, 15.

[5] Kendall, H.A., Lobao, L.M. and Sharp, J.S. (2006) Public Concern with Animal Well-Being: Place, Social Structural Location, and Individual Experience. Rural Sociology, 71, 399-428. http://dx.doi.org/10.1526/003601106778070617

[6] Tonsor, G., Olynk, N.J. and Wolf, C. (2009) Consumer Preferences for Animal Welfare Attributes: The Case of Gestation Crates. Journal of Agricultural and Applied Economics, 41, 713-730.

[7] McKendree, M.G.S., Widmar, N.O., Ortega, D.L. and Foster, K.A. (2013) Consumer Preferences for Verified PorkRearing Practices in the Production of Ham Products. Journal of Agricultural and Resources Economics, 38, 397-417. http://ageconsearch.umn.edu/bitstream/165935/2/JARE,Dec2013,\%237,McKendree,pp397G\%C3\%87\%C3\%B4417.pd $\underline{\mathrm{f}}$

[8] McKendree, M.G.S., Croney, C.C. and Widmar, N.J.O. (2014) Effects of Demographic Factors and Information Sources on United States Consumer Perception of Animal Welfare. Journal of Animal Science, 92, 3161-3173. http://dx.doi.org/10.2527/jas.2014-6874

[9] U.S. Census Bureau (2010) DP-1 Profile of General Population and Housing Characteristics: 2010, 2010 Demographic Profile Data. http://factfinder.census.gov/faces/tableservices/jsf/pages/productview.xhtml?pid=DEC_10_DP_DPDP1\&prodType=ta ble

[10] U.S. Census Bureau (2008-2012) DP01: Selected Economics: 2008-2012 American Community Survey 5-Year Estimates. http://factfinder.census.gov/faces/tableservices/jsf/pages/productview.xhtml?pid=ACS_12_5YR_DP03\&prodType=tab le

[11] U.S. Census Bureau (2010) Annual Estimates of Housing Units for the United States, Regions, Divisions, States and Counties: April 1, 2010 to July 1, 2013: 2013 Population Estimates. 
http://factfinder.census.gov/faces/tableservices/jsf/pages/productview.xhtml?pid=PEP_2013_PEPANNHU\&prodType table

[12] Finn, A. and Louviere, J.J. (1992) Determining the Appropriate Response to Evidence of Public Concern: The Case of Food Safety. Journal of Public Policy and Marketing, 11, 12-25.

[13] Marley, A.A.J. and Louviere, J.J. (2005) Some Probabilistic Models of Best, Worst, and Best-Worst Choices. Journal of Mathematical Psychology, 49, 464-480. http://dx.doi.org/10.1016/j.jmp.2005.05.003

[14] Wolf, C.A. and Tonsor, G.T. (2013) Dairy Farmer Policy Preferences. Journal of Agricultural and Resource Economics, 38, 220-234.

[15] Pruitt, J.R., Tonsor, G.T., Brooks, K.R. and Johnson, R.J. (2014) End User Preference for USDA Market Information. Food Policy, 47, 24-33. http://dx.doi.org/10.1016/j.foodpol.2014.04.008

[16] Train, K.E. (2003) Discrete Choice Methods with Simulation. Cambridge University Press, Cambridge. http://dx.doi.org/10.1017/CBO9780511753930

[17] UCLA Statistical Consulting Group (2015) Regressions with Stata Chapter 40 beyond OLS. http://www.ats.ucla.edu/stat/stata/webbooks/reg/chapter4/statareg4.htm

[18] Dillman, D.A. (2007) Mail and Internet Surveys: The Tailored Design Method: 2007 with New Internet, Visual and Mixed-Mode Guide. 2nd Edition, Wiley, Hoboken.

[19] Hensher, D. and Greene, W. (2010) Non-Attendance and Dual Processing of Common-Metric Attributes in Choice Analysis: A Latent Class Specification. Empirical Economics, 39, 413-426. http://dx.doi.org/10.1007/s00181-009-0310-x

[20] Widmar, O., Nicole, J. and Ortega, D.L. (2014) Comparing Consumer Preferences for Livestock Production Process Attributes across Products, Species, and Modeling Methods. Journal of Agricultural and Applied Economics, 46, 375391.

[21] Gao, Z.F., House, L.A. and Bi, X. (2012) Finding True Consumer Attitudes: Do Validation Questions Help? Food and Resource Economics Department, University of Florida. http://ageconsearch.umn.edu/bitstream/123922/1/aaea-poster-05-18.pdf

[22] Rothgerber, H. and Mican, F. (2014) Childhood Pet Ownership, Attachment to Pets, and Subsequent Meat Avoidance. The Mediating Role of Empathy towards Animals. Appetite, 79, 11-17. http://dx.doi.org/10.1016/j.appet.2014.03.032

\section{List of Abbreviations}

MNL $=$ multinomial logit.

$\mathrm{RPL}=$ random parameters logit. 